\title{
An investigation of the polarization dependence of a temperature sensor based on an optical microfiber coupler
}

\author{
Lin Bo $^{\mathrm{a}^{*}}$, Pengfei Wang ${ }^{\mathrm{a}, \mathrm{b}}$, Yuliya Semenova ${ }^{\mathrm{a}}$, Gilberto Brambilla ${ }^{\mathrm{b}}$, and Gerald Farrell ${ }^{\mathrm{a}}$ \\ ${ }^{a}$ Photonics Research Centre, Dublin Institute of Technology, Kevin Street, Dublin, Ireland; \\ ${ }^{\mathrm{b}}$ Optoelectronics Research Centre, University of Southampton, Southampton, SO17 1BJ, UK
}

\begin{abstract}
Abstract: The dependence on polarization of the performance of a microfiber coupler based temperature sensor is experimentally investigated. The optical microfiber coupler based temperature sensor has a diameter circa $2 \mu \mathrm{m}$ and can sense temperature in the range from $100^{\circ} \mathrm{C}$ to $1000^{\circ} \mathrm{C}$, with an average sensitivity of $18.9 \mathrm{pm} /{ }^{\circ} \mathrm{C}$. It is shown that different polarization states of the input signal have a significant influence on the proposed temperature sensing accuracy, with a estimated peak error of $63^{\circ} \mathrm{C}$ at $1000^{\circ} \mathrm{C}$.
\end{abstract}

Keywords: Optical microfiber, fiber coupler, temperature sensor, polarization dependence

\section{INTRODUCTION}

Since being first developed in 2003 [1], optical microfiber and nanowire based photonic devices have been extensively investigated for applications in optical sensing and communication systems [2]. The structure of a tapered fiber microcoupler was first presented in Ref. [3]. Recently, research on an optical microfiber coupler capable of broadband singlemode operation has offered potential new applications in the fields of high performance fiber lasers and optical coherence tomography [4]. Furthermore, the large evanescent field of the microfiber makes the micro-coupling region very sensitive to the surrounding measurands, allowing for the development of a range of fiber optic sensors with high sensitivity and microscale dimensions $[1,2]$.

The polarization dependence of a microfiber has been investigated in [5] and the results suggest new possibilities for polarization discrimination and control within microfiber based photonic devices, such as high-resolution optical fiber sensors, resonators and fiber lasers.

Recently highly sensitive temperature sensors based on a full or half microfiber coupler (MFC) have been presented $[6,7]$. The maximum sensitivity of such sensors can reach circa $36.6 \mathrm{pm} /{ }^{\circ} \mathrm{C}$, which is comparable to that achievable with the conventional optical fiber temperature sensors. However the polarization dependence of a microfiber coupler as a function of temperature has not been investigated to date. Experience has shown that polarization dependence is frequently a key limitation of many optical fiber sensors and so an investigation of the polarization dependence of an MFC based sensor is important.

In this paper, we present an investigation of the polarization dependence of a microfiber coupler based temperature sensor, which has a temperature range from $100^{\circ} \mathrm{C}$ to $1000^{\circ} \mathrm{C}$ with an average temperature sensitivity of $18.9 \mathrm{pm} /{ }^{\circ} \mathrm{C}$. From the experimental result it can be concluded that the performance of such a microfiber coupler based temperature sensor is sensitive to changes in the polarization state of the input light.

\section{FABRICATION OF MICROFIBER COUPLER}

The taper drawing system used is based on a ceramic microheater (CMH-7019, NTT-AT). A low-loss MFC was fabricated from two standard telecom optical singlemode fibers (SMF-28, Corning) using the microheater brushing technique [8]. A microfiber coupler comprises two conical transition regions, a central uniform waist region and two input ports (P1 and P2) and two output ports (P3 and P4): light injected from P1 or P2 exits the microfiber coupler from $\mathrm{P} 3$ and $\mathrm{P} 4$. The lengths of the tapered and uniform waist regions are $\sim 25 \mathrm{~mm}$ and $\sim 5 \mathrm{~mm}$ respectively [9]. The microfiber

*bo.lin@mydit.ie ; phone: +3531402 4812; fax: +35314024690 
coupler spectral characterization was carried out using a polarized broadband amplified spontaneous emission source (Fiber Coupled SLD, Thorlabs), with a wavelength range of 1500-1600 nm, connected to P1 and an optical spectrum analyzer (OSA) (86142B, Agilent) connected to P3. The transmission spectrum (at $900^{\circ} \mathrm{C}$ ) is presented in Fig. 1 which shows the expected multi-dip spectral pattern for the optical fiber coupler.

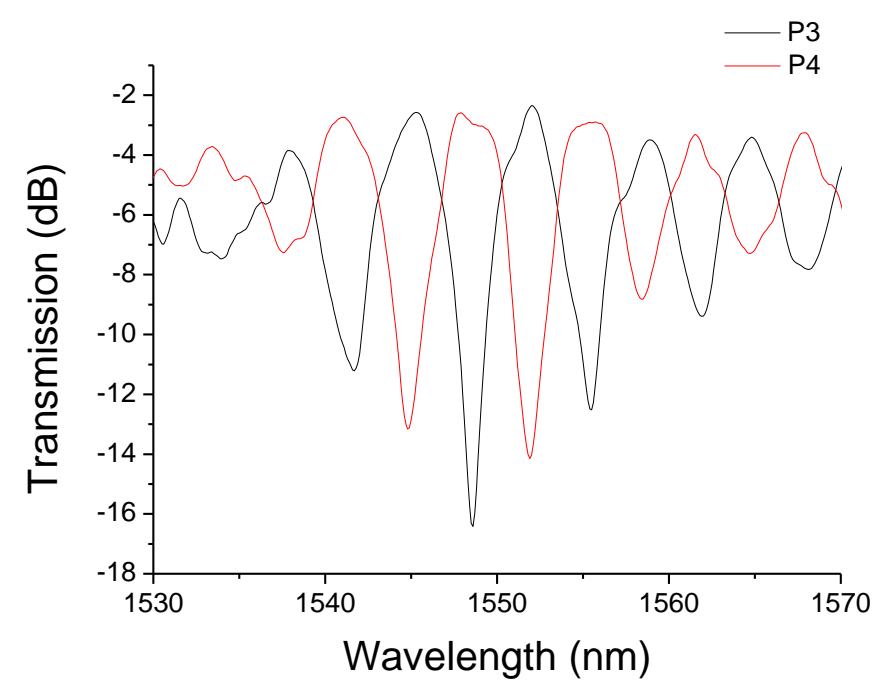

Fig.1. Spectral responses of the two output ports (P3 and P4).

\section{MEASUREMENT OF THE TEMPERATURE AND POLARIZATION DEPENDENCIES}

To investigate the temperature sensing performance and the effect of polarization for the microfiber coupler, an experimental setup shown in Fig. 2 was used. A manual polarization controller (FB51, Thorlabs) was placed between the broadband source and the microfiber coupler to change the polarization state of the input signal launched into P1. The output signal from P3 was connected to the OSA.

Polarization Controller Microfiber Coupler

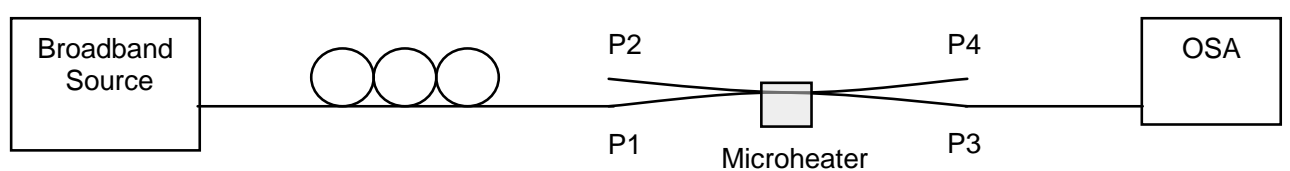

Fig. 2. Schematic diagram of experimental setup

Initially a characterization of the temperature sensing performance of the coupler was carried out without any changes to the polarization state. This temperature characterization was carried using the same microheater used to fabricate the microfiber coupler, as the heater can reach temperatures in excess of $1700{ }^{\circ} \mathrm{C}$. The uniform section of the taper waist of the microfiber coupler was inserted into the center of the slot in the microheater and transmission spectra were recorded at different temperatures up to $1000^{\circ} \mathrm{C}$. The microheater temperature was changed by increasing the current flowing into the microheater from $1.1 \mathrm{~A}$ to $4.8 \mathrm{~A}$ with intervals of circa $0.4 \mathrm{~A}$. The measurements were taken every 5 minutes to ensure a stable temperature had been achieved. Fig. 3 (a) shows some examples of measured spectra for temperatures of $700^{\circ} \mathrm{C}, 800^{\circ} \mathrm{C}$ and $900^{\circ} \mathrm{C}$. A temperature increase results in a redshift of the spectral response. As an example of the use of the device as sensor, Fig. 3 (b) shows the dip shift with temperature for the dip series starting at $1542.7 \mathrm{~nm}$ at $700^{\circ} \mathrm{C}$, from which it can be determined that the typical temperature sensitivity of this microfiber coupler based sensor is circa $18.9 \mathrm{pm} /{ }^{\circ} \mathrm{C}$ over a temperature range from $100^{\circ} \mathrm{C}$ to $1000^{\circ} \mathrm{C}$. 


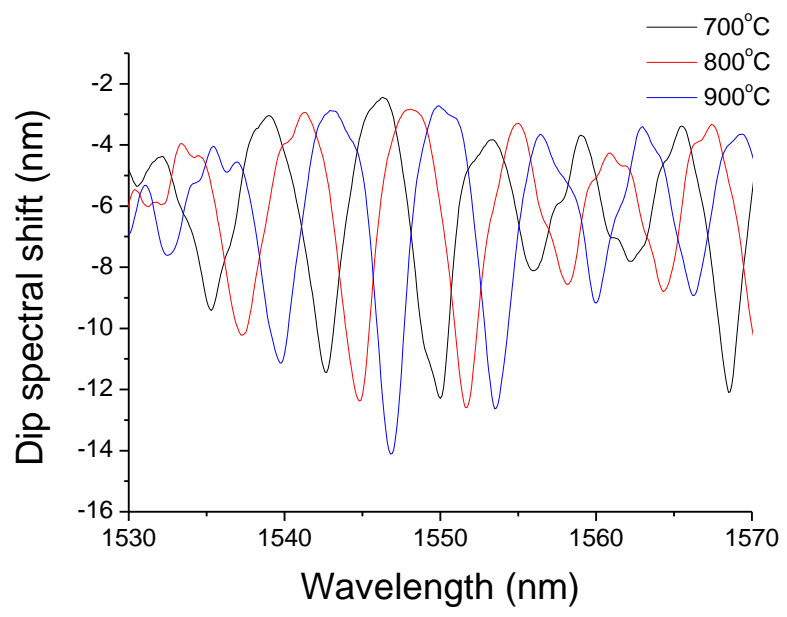

(a)

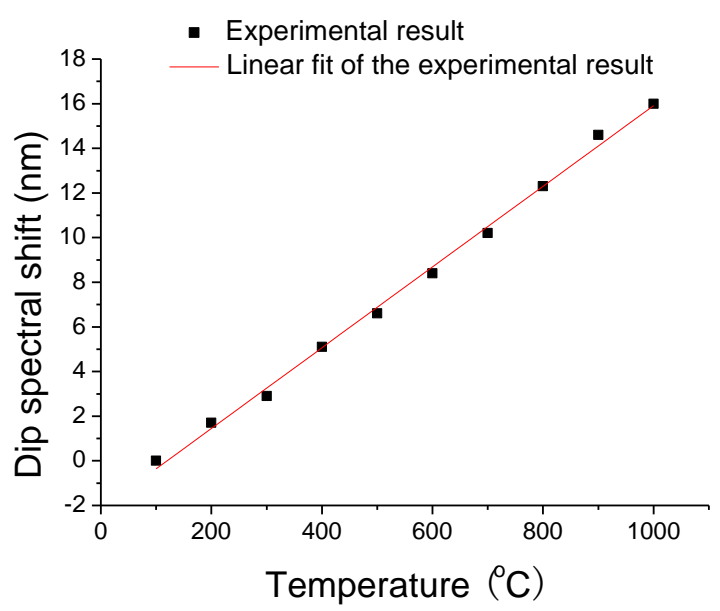

(b)

Fig.3. (a) Spectral response of the microfiber coupler for different temperatures $\left(700^{\circ} \mathrm{C}, 800^{\circ} \mathrm{C}\right.$ and $\left.900^{\circ} \mathrm{C}\right)$ for the same polarization state $\left(0^{\circ}\right)$ of the input light. (b) Dip shift versus temperature (from $100^{\circ} \mathrm{C}$ to $1000^{\circ} \mathrm{C}$ ).

The polarization dependence of the microfiber coupler sensor was then measured at each temperature. The polarization state of the input signal was rotated from $0^{\circ}$ to $90^{\circ}$ with an interval of $15^{\circ}$ using a manual polarization controller in order to collect polarization dependent spectral response using the OSA. Fig. 4 shows the dip spectral shifts for different polarization states of the input signal at each temperature. Table 1 shows an analysis of the results of Fig. 4 Setting the $0^{\circ}$ polarization state as the baseline value (i.e. $0 \mathrm{~nm}$ dip shift), the worst case dip shift for each polarization state and the set temperature at which it occurs are listed in Table 1. The effective temperature error for each polarization state is also calculated using the sensitivity of sensor determined from Fig. 3 (b). The results indicate that the microfiber coupler temperature sensor is polarization dependent, which can lead to significant temperature measurement errors.

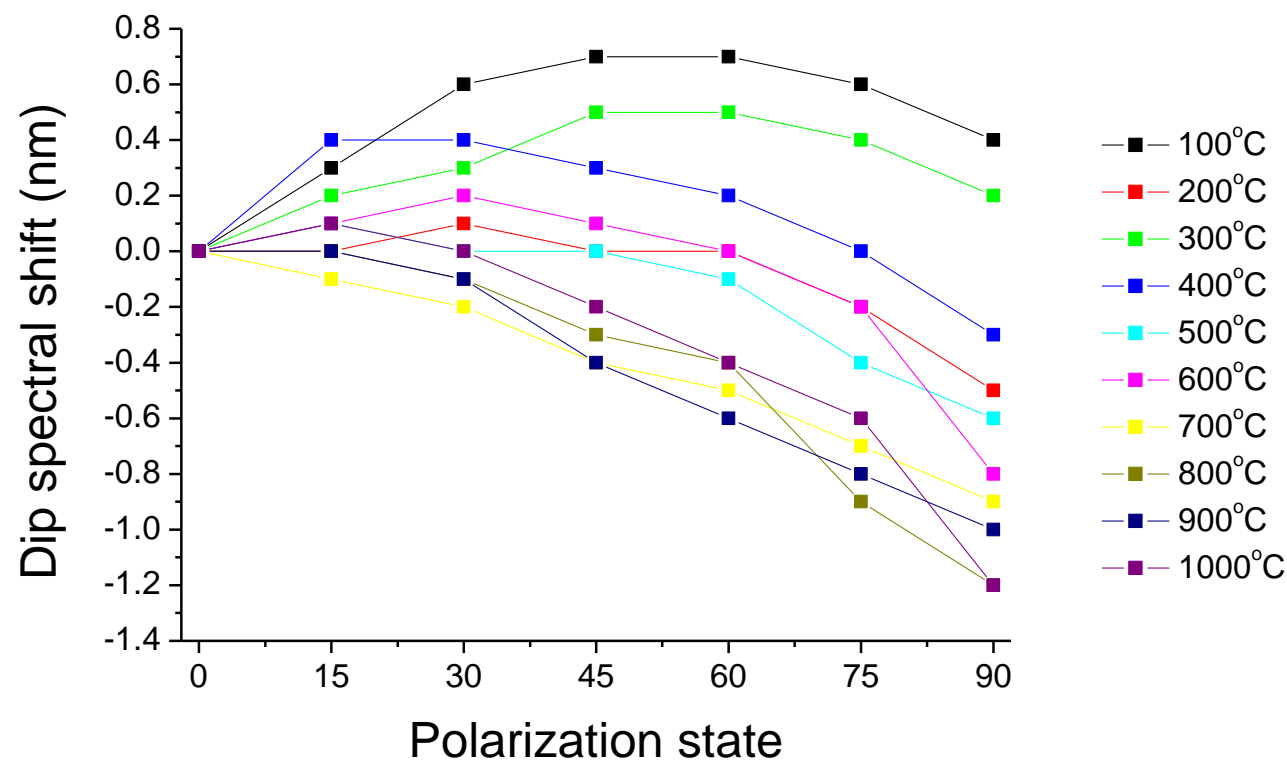

Fig.4. Dip spectral shift versus polarization states at each temperature. 
Table 1. Analysis of the result of Fig. 4 showing the estimated polarization induced temperature error.

\begin{tabular}{|c|c|c|c|}
\hline $\begin{array}{c}\text { Polarization } \\
\text { state }\end{array}$ & $\begin{array}{c}\text { Worst case } \\
\mathbf{d i p} \text { shift(nm) }\end{array}$ & $\begin{array}{c}\text { Set Temperature at which } \\
\text { worst case dip shift occurs }\left({ }^{\circ} \mathbf{C}\right)\end{array}$ & $\begin{array}{c}\text { Temperature } \\
\text { error }\left({ }^{\circ} \mathbf{C}\right)\end{array}$ \\
\hline 15 & 0.4 & 400 & 21.2 \\
\hline 30 & 0.6 & 100 & 31.7 \\
\hline 45 & 0.7 & 100 & 37.0 \\
\hline 60 & 0.7 & 100 & 37.0 \\
\hline 75 & 0.9 & 800 & -47.6 \\
\hline 90 & 1.2 & 1000 & -63.9 \\
\hline
\end{tabular}

\section{CONCLUSION}

An investigation of polarization dependent performance of a microfiber coupler temperature sensor is presented for a sensor with a sensitivity of $18.9 \mathrm{pm} /{ }^{\circ} \mathrm{C}$ within a temperature range from $100^{\circ} \mathrm{C}$ to $1000^{\circ} \mathrm{C}$. Analysis of the measured polarization dependence of the microfiber coupler based temperature sensor indicates that the proposed fiber sensor is sensitive to the different polarization states of the input light and this in turn can result in significant temperature measurement errors. .

\section{ACKNOWLEDGMENTS}

Lin Bo would like to thank the International Centre for Graduate Education in micro \& nano Engineering (ICGEE) for her PhD funding support and also Mr. Michael Neary of the School of Manufacturing and Design Engineering at DIT for assistance in preparing the fabrication setup. Pengfei Wang is funded by the Irish Research Council for Science, Engineering and Technology (IRCSET) and the European Union Marie-Curie Actions under FP7.

\section{REFERENCES}

[1] Tong, L. M, R. R. Gattass, J.B. Ashcom, S. L. He, J. Y. Lou, M. Y. Shen, I. Maxwell, and E. Mazur, "Subwavelength-diameter silica wires for low-loss optical wave guiding," Nature, Vol. 426, No.6968, 816-819, (2003).

[2] Gilberto Brambilla, Fei Xu, Peter Horak, Yongmin Jung, Fumihito Koizumi, Neil P. Sessions, Elena Koukharenko, Xian Feng, Ganapathy S. Murugan, James S. Wilkinson, and David J. Richardson. "Optical fiber nanowires and microwires: fabrication and applications," Advances in Optics and Photonics 1, 107-161 (2009).

[3] G. Kakarantzas, T. E. Dimmick, T. A. Birks, and P. S. Russell, "Fused taper fibre microcoupler," Optical Fiber Communication Conference, OSA Technical Digest Series (Optical Society of America, 2000), paper TuB6.

[4] Yongmin Jung, Gilberto Brambilla, and David J. Richardson, "Optical microfiber coupler for broadband singlemode operation," Optical Express, Vol.17, No. 7, 5273-5278 (2009).

[5] Yongmin Jung, Gilberto Brambilla, and David J. Richardson, "Polarization-maintaining optical microfiber," Opt. Lett. 35, 2034-2036 (2010).

[6] Pengfei Wang, Ming Ding, G. Brambilla, Y. Semenova,Qiang Wu and G. Farrel, "High temperature performance of an optical microfibre coupler and its potential use as a sensor," Electronic Letters, Vol. 48 No. 5. (2012).

[7] Ming Ding, Pengfei Wang, and Gilberto Brambilla "A microfiber coupler tip thermometer," Optical Express, Vol.20, No. 5, 5402-5408 (2012).

[8] Gilberto Brambilla, Vittoria Finazzi, and David Richardson, "Ultra-low-loss optical fiber nanotapers," Opt. Express 12, 2258-2263 (2004).

[9] Timothy A. Birks and Youwei W. Li, "The shape of fiber tapers," Journal of Lightwave Technology. Vol. 10, No. 4, 432-438 (1992). 